\title{
A \\ Primeiros passos para a elaboração de um Modelo Psicossociológico do Comportamento Eleitoral: estudo dos eleitores de João Pessoa na campanha de 1992
}

\author{
Leoncio Camino \\ Eleneide A. da Silva \\ Sânzia M. de Souza \\ Universidade Federal da Paraíba
}

\begin{abstract}
Resumo
O debate sobre os fatores intervenientes no processo eleitoral tem-se polarizado entre duas perspectivas: a sociológica e a psicológica. Situando a escolha eleitoral num processo dialético, Camino, Torres e Da Costa (1995) organizaram os fatores que influenciam no voto utilizando duas dimensões independentes. A primeira, constituída pelas duas vertentes do processo de construção da realidade política: as alternativas políticas concretas e o ato individual de escolha. A segunda constituída por três níveis de análise: o observacional, o mediacional e o metateórico. Esta sistematização guiou um conjunto de pesquisas eleitorais com estudantes realizadas por Camino e colaboradores (1995). Os resultados permitiram elaborar um Modelo Psicossociológico, no qual pressupõe-se que a Escolha Eleitoral é um processo que se estabelece desde a inserção do indivíduo nas organizações da sociedade até o momento de depositar seu voto na urna. O modelo localiza etapas do processo e as relaciona com a escolha eleitoral. Este trabalho apresenta uma pesquisa cujos resultados confirmam as principais relações propostas no "Modelo Psicossociológico". Observa-se que os eleitores com par-
\end{abstract}


8 L. Camino, E. A. da Silva e S. M. de Souza

ticipação social são os que mais acreditam na eficácia das atividades eleitorais. Constata-se também que as diversas formas de participação social modelam visões próprias no que concerne à estrutura social. A visão da estrutura social, enquanto matriz ideológica, influencia também a escolha eleitoral. Os dados mostraram ainda que existe uma relação estreita entre a ideologia do partido de simpatia e o tipo de representação da estrutura social. Finalmente, discutem-se as perspectivas que o modelo abre no estudo do comportamento eleitoral.

\author{
Palavras-chave: \\ Modelo \\ Psicossociológico, \\ Comportamento \\ Eleitoral, \\ Participação \\ Social
}

Key-words: Psychological Model, Social Participation,

Electoral

Behaviour.
Abstract

Proposing a Psychosociological Model of Electoral Choice: the João Pessoa 1992 election's case. The discussion of the intervening factors in the electoral process has polarized into two perspectives: the sociological and the psychological. Establishing electoral choice as a dialectical process, Camino, Torres and Da Costa (1995) used two independent dimensions to systematize the factors that influence the vote. The first one consists of the two building processes of political reality: concrete political alternatives and individual acts of choice. The second formed by three levels of analysis: observation, inference and metatheory. This systematization led to a line of electoral research done by Camino and collaborators with students. The results allowed the elaboration of a psychosociological Model proposing that Electoral Choice is a process established from the insertion of the individual in the society organizations up to the moment of voting. The model locates stages of the process and relates them to the electoral choice. The present work presents a study that confirms the main relationships proposed in the "psychosociological model". It is observed that voters with social participation believe more in the efficacy of electoral activities. There is also evidence that the various forms of social participation shape peculiar views concerning the social structure. The social structure view, as an ideological matrix, also influences electoral choice. The data show that there is a close relationship between the voter's party ideology and the type of representation of social structure. Finally, the perspectives opened by the model in the study of the electoral behaviour are discussed. 

a noção de participação indireta ou Democracia Representativa. Considera-se que, frente à crescente complexidade das sociedades industriais, a única maneira de garantir a democracia é a implantação do Sistema Representativo (Stuart Mill, 1861/1981).

Na medida em que vai sendo considerada elemento essencial da Democracia, a representação política passa também a ser entendida como um conjunto de regras e de procedimentos destinados à constituição de um governo e à formação das decisões políticas de uma sociedade (Bobbio, 1986). No sistema representativo, assim constituído, o voto ocupa um lugar essencial. Nesta visão é inconcebível uma democracia sem eleições.

\section{O voto como um dos elementos do processo político}

A propriedade mais marcante do voto na democracia representativa é a de ser um ato estritamente individual. O liberalismo promove a liberdade do indivíduo frente ao Estado (Stuart Mill, 1861/1981). Mas a sua desconfiança frente às massas (Le Bon, 1895; Sighele, 1898/ 1954; Tarde, 1898) o leva a enfatizar também a necessidade de criar condições para que a escolha eleitoral se faça em isolamento, pois as decisões tomadas numa assembléia não representariam os verdadeiros interesses dos participantes (Michels, 1914/1982). Promove-se, portanto, a liberdade dos indivíduos simultaneamente frente ao estado e frente aos outros indivíduos.

A partir desta visão individualista, o voto foi inicialmente estudado como um ato estritamente individual, embora pudesse ser influenciado por diversos fatores sociais. O debate sobre a natureza destes fatores polariza-se entre duas perspectivas. Numa, considera-se que os principais determinantes da escolha eleitoral são as caraterísticas sociais dos eleitores, entendidas aqui como classe social, religião e local de residência (Lazarsfeld, Berelson \& Gaudet, 1948; Berelson, Larzarsfeld $\&$ McPhee, 1954). Na outra perspectiva sustenta-se que a compreensão da natureza do voto começa e termina no conhecimento da mente do 
10 L. Camino, E. A. da Silva e S. M. de Souza

eleitor: suas atitudes e motivos sociais (Campbell, Gurin \& Miller, 1954; Campbell, Converse, Miller \& Stokes, 1960).

Hoje coloca-se a decisão eleitoral no quadro mais amplo do processo e do sistema eleitoral, como parte constitutiva do processo político global ${ }^{1}$. Assim, segundo Fisichiella (1986), o comportamento eleitoral é "o processo de formação e de expressão das preferências individuais frente às alternativas políticas sujeitas à crítica do voto" (p. 189). Esta definição além de destacar os dois aspectos constitutivos do comportamento eleitoral: $\mathrm{o}$ ato individual de escolher um candidato e a existência concreta de alternativas políticas reais, afirma também a necessidade de entender os dois aspectos como pólos dialeticamente ligados de um único processo político.

\section{Primeira organização dos fatores intervenientes na escolha eleitoral}

No final da década de 80, Camino e colaboradores (Camino, 1996a; Camino, Torres \& DaCosta, 1995) organizaram os diversos fatores que podem influenciar o ato de votar utilizando, como um dos eixos organizadores, a distinção introduzida por Fisichiella (1986) entre a existência na Sociedade de alternativas políticas e o ato individual de escolher uma delas pelo voto. Esta distinção permitiu uma primeira classificação dos fatores: os concernentes à vertente objetiva das alternativas políticas concretas colocadas na Sociedade e os relacionados com a vertente subjetiva do processo individual de escolha.

Ao mesmo tempo, os fatores pertencentes a cada uma destas duas vertentes da realidade social, pelo fato de possuírem naturezas heterogêneas, podem ser organizados em três níveis de análise: o observacional, o mediacional e o metateórico.

Assim, para classificar os fatores intervenientes no processo eleitoral, Camino et al. (1995) usaram duas dimensões independentes. A primeira, constituída pelas duas vertentes do processo de construção da realidade política. A segunda, constituída pelos três níveis de análise da realidade.

A primeira dimensão sustenta-se na abordagem dialética dos processos de construção da realidade social (Berger \& Luckmann, 
1973; Camino, 1995; Vala, 1996). A existência das duas vertentes não implica a existência de duas realidades sociais, mas sugere que a única realidade social é construída pela interação dialética de processos diferentes, porém complementares.

A segunda dimensão apoia-se em critérios metodológicos. Assim, no nível observacional, classificam-se fatores conjunturais e comportamentais diretamente observáveis nas campanhas eleitorais. No nível mediacional, situam-se as variáveis cognitivas e afetivas que podem ser vistas tanto como decorrentes da cultura, quanto próprias dos indivíduos. Estas mediações não são diretamente observáveis, mas inferidas a partir de fatos culturais ou da conduta das pessoas. Finalmente, no nível metateórico colocam-se os processos intergrupais e macro-sociais, nos quais se geram as mediações cognitivas e afetivas do nível anterior.

A partir das duas dimensões citadas, vertentes da construção da realidade social e níveis de análise, Camino (1996a) classificou os diversos fatores relevantes ao estudo da decisão eleitoral. A forma gráfica de organizar esta classificação (Quadro 1) explicita já certos enunciados teóricos. Colocando, lado a lado, no mesmo nível de análise, fatores conjunturais e comportamentais, reafirma-se que as ações individuais se realizam como tentativas particulares de inserção num conjunto de ações coletivas preexistentes. $\mathrm{O}$ mesmo acontece com os fatores culturais e os psicológicos, dado que as mediações cognitivas e afetivas dos sujeitos originam-se em matrizes de idéias e de representações preexistentes na Sociedade.

Mas situar o processo eleitoral entre dois pólos não implica a aceitação de nenhum tipo de dualismo. A distinção, expressa no Quadro 1 em forma de oposição horizontal, limita-se aos dois primeiros níveis de análise. Já no terceiro nível, pretende-se mostrar, mudando a apresentação para planos horizontais, que o que se denomina de vertentes de construção objetiva e subjetiva da realidade possui de fato uma origem comum: as relações de produção. Na perspectiva psicossociológica adotada, as disposições políticas subjetivas e as alternativas políticas objetivas não são outra coisa que dois aspectos (cara e coroa) da mesma realidade: o desenvolvimento de setores sociais freqüentemente em conflito (Camino, 1996b). 
12 L. Camino, E. A. da Silva e S. M. de Souza

Analisando os fatores assim organizados, observa-se que no nível observacional situam-se aspectos da conjuntura como a campanha eleitoral, candidaturas, programas, propaganda e atividades organizadas como comícios e carreatas (Quadro 1). Nesse nível analisa-se também a inserção do eleitor na campanha, através da procura de informação e da participação em atividades da campanha eleitoral, tais como conversas, comícios, carreatas e boca de urna.

No nível mediacional analisam-se tanto as culturas e tradições políticas existentes na Sociedade quanto as disposições cognitivas e afetivas dos indivíduos, pois tanto a campanha eleitoral quanto a participação dos eleitores não se dá num vazio. Por um lado, as campanhas eleitorais desenvolvem-se numa Cultura Política determinada que inclui normas e crenças sobre a política. Por outro lado, as pessoas teriam-se apropriado, em maior ou menor grau, de um conjunto de representações, atitudes e opiniões políticas. Estas, de acordo com o grupo de Michigam (Campbell, Converse, Miller \& Stokes, 1960), se integrariam na Identificação Partidária, fator decisivo do voto, que seria entendida como "compromisso forte, aderência persistente, que influencia fortemente em como os eleitores olham o mundo político" (p. 146).

Finalmente, no nível psicossociológico, considera-se que a relação entre os aspectos objetivo e subjetivo do comportamento político podem ser analisados no nível das relações intergrupais, no qual os dois aspectos seriam reflexos do processo estabelecido nas relações de produção. Este nível constitui-se, por um lado, pela estrutura sócioeconômica, formada por grupos sociais com interesses conflitantes; por outro lado, pela estrutura psicossocial, na qual se desenvolvem tanto as representações de pertença social quanto as ações derivadas destas representações. Supõe-se que, tanto a pertença aos diversos grupos sociais, formadora da identidade social dos indivíduos quanto às alternativas políticas originadas nos interesses dos diversos grupos sociais, são ambas oriundas das divisões sociais, próprias das relações de produção e dos conflitos ali gerados (Camino, 1992).

A relação entre as vertentes objetiva e subjetiva da realidade social efetua-se, portanto, através do processo de construção das 


\section{QUADRO 1}

Relevamento do conjunto de fatores que intervém no comportamento eleitoral em funcão dos níveis de análise (Camino, 1996a).

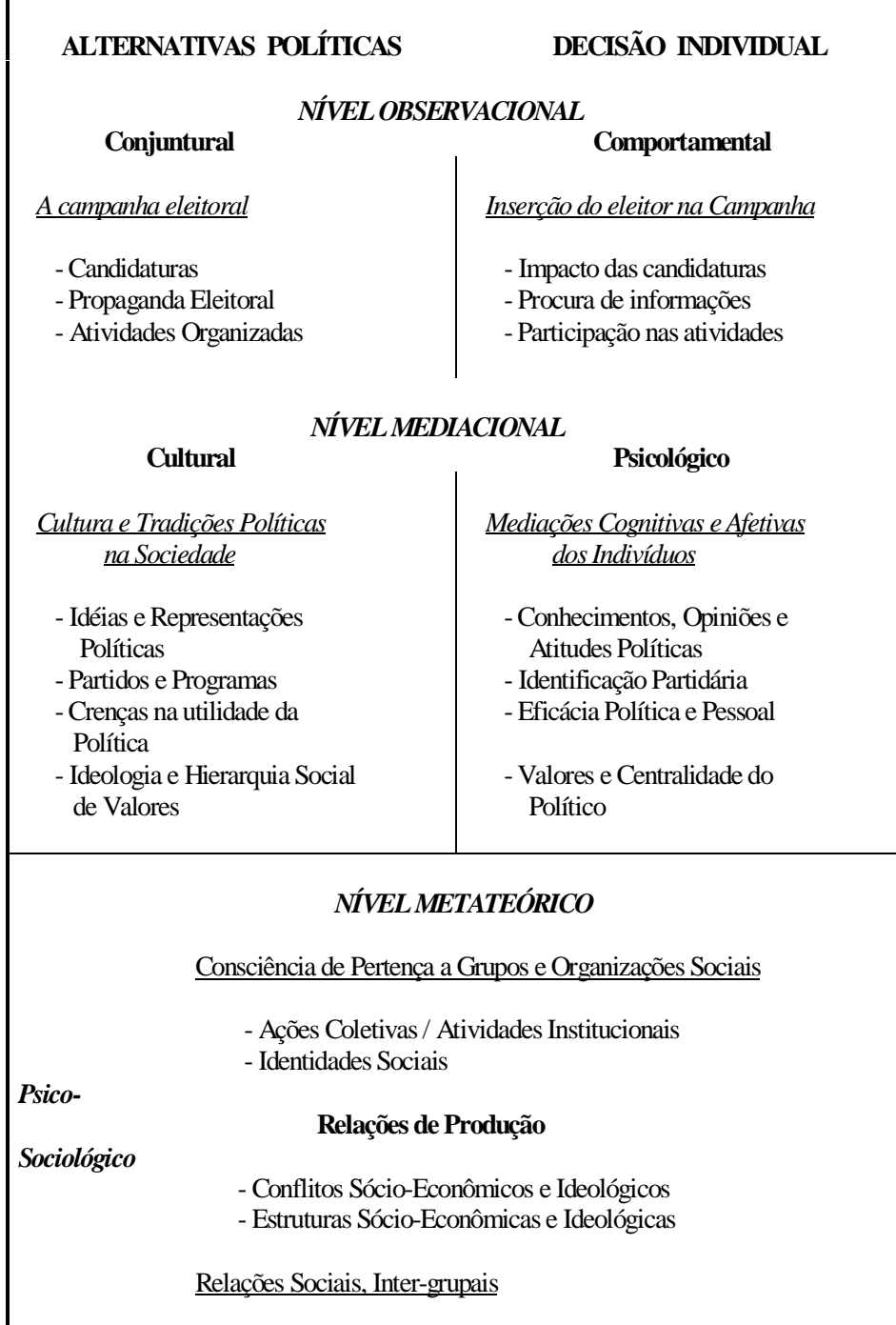


14 L. Camino, E. A. da Silva e S. M. de Souza

Identidades Sociais. Estas nascem no interior das relações intergrupais (Tajfel, 1981; Turner, 1981) e se desenvolvem na comparação dos próprios grupos com os grupos externos. Trata-se, pois, de construções mentais, de representações de seus grupos e dos outros grupos. Este "jogo de reconhecimentos" (Penna, 1989) se origina nas relações de poder e se dá em duas direções, do conflito às identidades e das identidades ao conflito; direções nem sempre coincidentes, mas que se articulam dinamicamente. Num certo sentido, pode-se afirmar que a identidade social se desenvolve nos conflitos intergrupais, mas pode-se afirmar igualmente que a identidade social é condição de mobilização para ações coletivas e movimentos sociais (Reicher, 1984).

Os partidos se constróem, igualmente, como alternativas políticas, na medida em que os grupos sociais procuram o poder para realizar seus interesses sociais. Neste sentido, a invenção "moderna" da Representação Política consiste precisamente na criação de mecanismos para absorver os conflitos de interesse, institucionalizando procedimentos capazes de dar voz aos interesses grupais, neutralizando os componentes desagregadores da atividade oposicionista, ao torná-la possível alternativa de governo (Balbachesvsky, 1989). Desde Stuart Mill (1861/1981) liga-se explicitamente a função institucional dos partidos à sua função de representação social ${ }^{2}$.

Primeiros estudos da escolha eleitoral na perspectiva psicossociológica

Utilizando o mapeamento apresentado no Quadro 1, Camino e colaboradores (Camino \& Da Costa, 1994; Camino et al., 1995; Da Costa, Torres, Burity \& Camino, 1994; Torres, 1992) realizaram, nas eleições de 1988, 1989 e 1990, três investigações com estudantes da Universidade Federal da Paraíba (UFPb). Na investigação de 1988 observou-se que as opiniões políticas dos estudantes não formavam esquemas coerentes em relação aos programas políticos existentes e, portanto, não explicavam suas opções eleitorais (Torres, 1992). Uma análise posterior dos dados, em termos de identificação partidária, permitiu constatar que aqueles que simpatizavam com algum partido possuíam uma certa consistência em suas opiniões políticas, opiniões que se relacionavam com a escolha eleitoral (Camino \& Da Costa, 1994). 
Nas investigações durante as eleições de 1989 e de 1990, os resultados não só confirmaram o papel importante da simpatia partidária na escolha eleitoral, mas mostraram também seu caráter ideológico. Nestes estudos, os estudantes eram convidados a descrever os setores sociais representados tanto pelo seu partido de simpatia (ou pelo partido ideal, no caso dos não simpatizantes) como pelos partidos com visão política oposta à deles. A análise das respostas permitiu constatar que a percepção da representação política do partido de simpatia e dos partidos opostos expressa a visão que os eleitores fazem da divisão da estrutura sócio-política, e que esta visão tem uma certa correspondência com os conteúdos ideológicos dos partidos de simpatia (Camino et al., 1995). No caso dos estudantes da UFPb, esta visão parece desenvolver-se principalmente através da participação nas organizações estudantis (Camino \& Da Costa, 1994; Da Costa et al., 1994).

Este conjunto de resultados permitiu constatar que as mediações afetivas e cognitivas da política (fatores do nível psicológico) desenvolvem-se nos quadros ideológicos das diversas instituições e organizações da sociedade civil (Camino, 1996b). Em outras palavras podese afirmar:

1. Que existem matrizes ideológicas que determinam a orientação política das pessoas.

2. Que essas matrizes são adquiridas na maneira peculiar em que as pessoas se inserem nos diversos grupos que compõem a sociedade civil.

3. Que a participação política é influenciada não só pelas matrizes ideológicas, mas também pelo conjunto de crenças sobre a utilidade da política.

Este conjunto de enunciados permitiu a elaboração de uma proposta de Modelo Psicossociológico para o Estudo do Comportamento Eleitoral.

Proposta de um Modelo Psicossociológico para o Estudo da Decisão Eleitoral

$\mathrm{Um}_{\mathrm{modelo}}{ }^{3}$ deve precisar: primeiro, o fenômeno que se deseja explicar (variável dependente); segundo, os fatores que participam da 
16 L. Camino, E. A. da Silva e S. M. de Souza

explicação (variáveis independentes) e finalmente, a natureza das relações que se deseja estabelecer entre o fenômeno e os fatores determinantes (perspectiva teórica).

No que se refere ao fenômeno que se deseja explicar, o voto, cabe uma reflexão preliminar. Como se pode analisar a decisão eleitoral que é um ato individual e, por lei, segredo? A escolha eleitoral tem sua medição específica na contagem de votos efetuada pela justiça eleitoral, cuja homologação consolida legalmente a escolha feita pelos eleitores. Mas é evidente que o estudo dos resultados oficiais é limitado e não permite entender os aspectos subjetivos do processo de escolha. Isto tem levado os pesquisadores a estudar, através de entrevistas e questionários, os aspectos da decisão eleitoral que mais lhes interessam. Assim, a decisão eleitoral e o processo de escolha podem ser avaliados através de variáveis tais como: a decisão de votar, o processo de escolha e a escolha feita.

No que concerne aos fatores listados no mapeamento inicial, os estudos com estudantes universitários, anteriormente citados, mostraram que certos fatores parecem desempenhar um papel importante no comportamento eleitoral. Assim, no nível observacional, variáveis comportamentais como a participação na campanha eleitoral, a busca de informações e o conhecimento das alternativas políticas parecem exercer uma influência positiva tanto na disposição a votar quanto no processo de escolha (Torres, 1992). No nível mediacional, crenças na eficácia política estão positivamente relacionadas com a disposição a votar. Finalmente, nos níveis mediacional e metateórico, fatores psicológicos como a identificação partidária e fatores psicossociológicos como a participação em organizações e instituições sociais desempenham um papel decisivo no tipo de escolha eleitoral.

Entretanto, resta entender como estes fatores se originam e de que maneira se relacionam entre si e com a escolha eleitoral. O Modelo Psicossociológico pressupõe que a formação da escolha eleitoral é um processo que se estabelece desde a inserção do indivíduo nas diversas organizações da sociedade civil ${ }^{4}$ até o momento de depositar seu voto na urna. $\mathrm{O}$ modelo procura localizar etapas importantes do processo e relacioná-las com três aspectos do comportamento de 
votar: a disposição a votar, o processo de escolha e o resultado da escolha eleitoral.

As diversas características sócio-demográficas (gênero, idade, classe social, escolaridade, renda familiar etc.), pelas quais se definem os diversos setores e grupos sociais, não afetariam diretamente o processo de decisão eleitoral, como pretendido pela escola de Columbia (Lazarsfeld, Berelson \& Gaudet, 1948). As características sóciodemográficas seriam condições necessárias, na medida em que indicariam a pertença virtual a um certo tipo de setor social, mas não condições suficientes, na medida em que outros fatores adicionais seriam necessários para explicar a identificação efetiva do sujeito com esse setor. Assim, ser mulher seria condição necessária, mas não suficiente, para explicar a identificação de uma mulher com o movimento feminino.

O modelo Psicossociológico pressupõe, portanto, que uma pessoa será afetada pelas suas características sócio-demográficas na medida em que se sentir membro e participar de grupos ou setores sociais constituídos por essas características. Neste sentido, a participação numa organização, que representa os interesses de um setor social, é um indicador (evidentemente não o único) dos sentimentos de pertença e de engajamento do indivíduo num setor social. Por exemplo, a participação ativa de uma pessoa numa organização trabalhista ou profissional expressará a pertença dessa pessoa à categoria social representada por essa organização. Assim, a participação social e as identidades a ela correlatas, ocupam um lugar central no Modelo Psicossociológico.

As relações que surgem da participação social são analisadas, no modelo (Figura 1), em duas direções. Na primeira, pressupõe-se que os eleitores com maior participação social apresentarão maior crença na Eficácia Política e, consequentemente, participarão mais da campanha eleitoral, demostrando maior disposição a votar. Na segunda direção espera-se uma relação entre as formas concretas de participação social e o posicionamento do eleitor na estrutura social. Este posicionamento social, expresso na identificação com uma das forças sociais percebidas na arena política, influenciará, por sua vez, a escolha eleitoral do eleitor, através de suas opiniões políticas e simpatia partidária. 


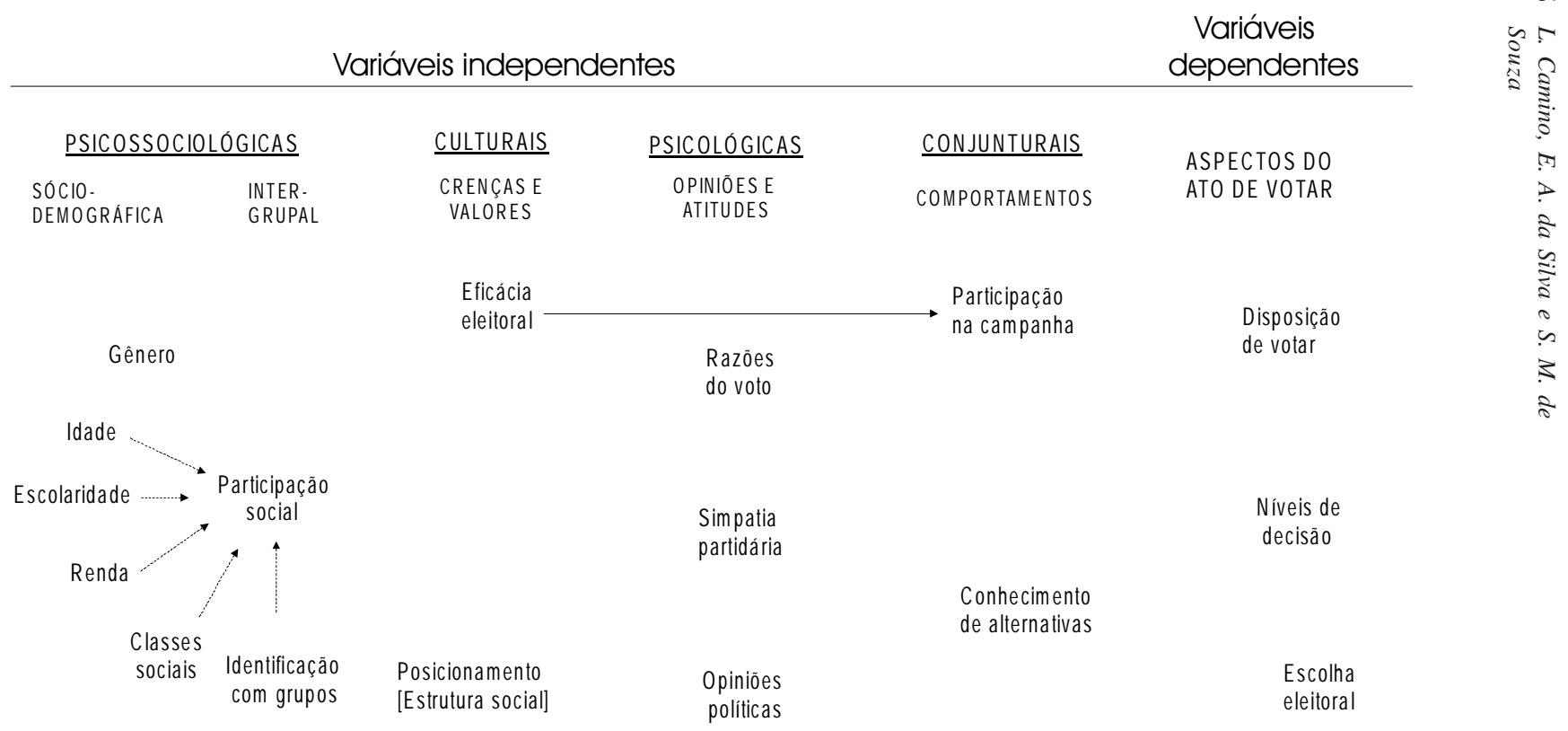


Diversos estudos desenvolvidos em João Pessoa mostram que a participação inicial em uma forma de organização social predispõe posteriormente os indivíduos a participarem de outras formas de participação política (Camino, 1995). Assim, as organizações trabalhistas, por exemplo, tendem a incentivar a participação política de seus membros, ao passo que certas organizações religiosas (as fundamentalistas, por exemplo), podem incitar sistemas de valores que não incentivem a política (Lima, 1993). Outras organizações religiosas, como as Comunidades Eclesiais de Base (CEBS) e as pastorais operárias, incentivam em seus membros a participação em movimentos populares e sindicais (Amado, 1988). No que concerne à crença na eficácia eleitoral, Gouveia, França, Da Costa e Camino (1997) observaram em eleitores de João Pessoa que a participação em movimentos sóciopolíticos e trabalhistas é melhor preditora da disposição a votar que outras formas de participação. Aliás, outros estudos mostram que se deve estabelecer relações específicas entre formas concretas de participação política e as crenças na eficácia de diversas formas de atividade política (França, 1995).

Finalmente, a suposição de que as formas de participação social influenciem o posicionamento político ideológico dos eleitores deriva da constatação clássica em Psicologia Social de que os membros assimilam dos grupos valores, normas e formas de autorepresentação (Camino, 1995). Neste sentido, os eleitores, ao participarem ativamente de diversos grupos ou instituições da vida social, assimilariam tanto os valores sociais destas formas de organização como as representações que estes grupos fazem da estrutura social. Da Costa et al. (1994) observaram que uma boa percentagem dos estudantes da $\mathrm{UFPb}$ que participam do movimento estudantil localiza-se na esquerda e possui uma visão da estrutura social denominada de "classista", no sentido que opõe de um lado os trabalhadores e do outro lado o capital. Torres (1992) constatou que os estudantes centristas possuem uma visão "sistêmica" da sociedade, pois consideram que o seu partido de simpatia representa todas as classes.

Verificação empírica de certos elementos do Modelo Psicossociológico 
20 L. Camino, E. A. da Silva e S. M. de Souza

O objetivo fundamental deste trabalho é testar partes do Modelo Psicossociológico da Escolha Eleitoral, utilizando os dados já obtidos numa pesquisa realizada com os eleitores de João Pessoa durante as eleições de 1992 (Gouveia et al., 1997). As relações a serem testadas neste trabalho encontram-se indicadas, na Figura 2, por setas entre as variáveis.

As setas pontilhadas (Figura 2) indicam relações específicas entre características sócio-demográficas e a participação em certas formas de organização social. Na medida em que organizações representam grupos com características específicas, estas características constituem condições necessárias, mas não suficientes, de participação nelas.

A participação, na perspectiva psicossociológica, desempenha um papel decisivo no processo de escolha eleitoral. Por um lado, ela influenciará o desenvolvimento das crenças na eficácia da participação eleitoral; crenças que, por sua vez, determinarão positivamente a disposição a votar. Por outro lado, a participação social influenciará tanto a maneira pela qual o eleitor percebe a estrutura social e se situa nela como a simpatia partidária que ele desenvolve. Finalmente, simpatia partidária e posicionamento ideológico afetarão o tipo de escolha eleitoral.

Método

A fim de verificar as relações propostas pelo Modelo Psicossociológico, analisaram-se, nesta perspectiva, os dados da pesquisa realizada por membros do Grupo de Pesquisa em Comportamento Político (Gouveia et al., 1997), durante a campanha para a eleição de prefeitos e vereadores em João Pessoa no mês de agosto de 1992.

Para proceder à escolha da amostra, constituída por 430 eleitores, os autores dividiram o universo da população de João Pessoa em 04 Setores Habitacionais, nos quais agruparam os diferentes bairros da cidade em função da infra-estrutura urbana, nível sócio-econômico e características sócio-culturais. A amostra de cada setor foi escolhida proporcionalmente ao número de moradores. Para cada setor foram sorteados bairros e para cada bairro foram sorteadas quadras. Em cada quadra foram sorteadas as casas e em cada casa foram sorteados os indivíduos a serem entrevistados para evitar a concentração de um 
Figura 2. Elementos do Modelo Psicossociológico do Comportamento Eleitoral a serem verificados neste trabalho

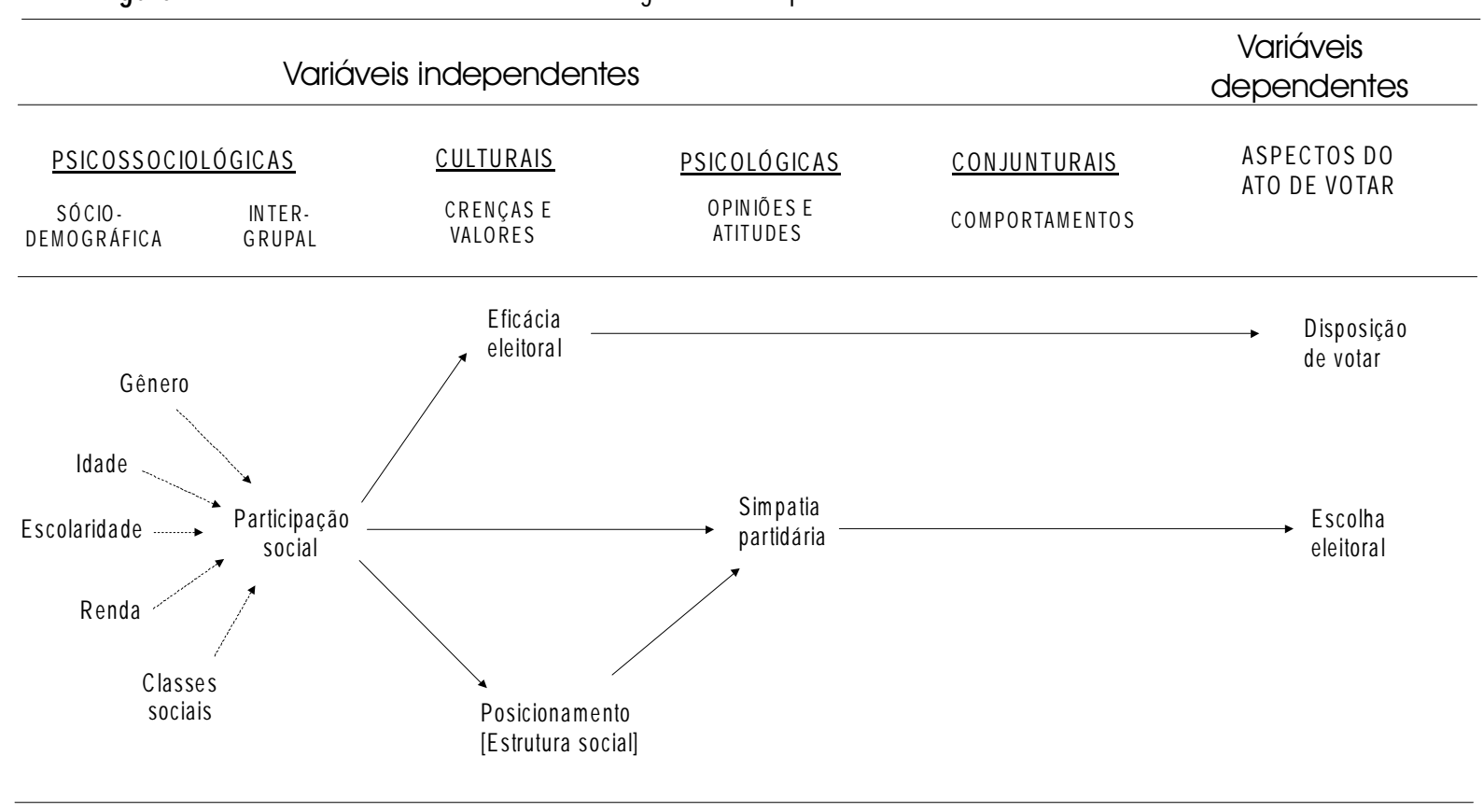


22 L. Camino, E. A. da Silva e S. M. de Souza

só tipo de sujeito. As entrevistas foram realizadas no fim-de-semana que antecedeu ao início do Horário Eleitoral Gratuito no rádio e na televisão.

\section{Instrumento}

Utilizou-se um roteiro de entrevista que abrangia os seguintes aspectos:

a. Medidas da escolha eleitoral:

1. Disposição a votar: Perguntava-se aos sujeitos se votariam caso as eleições não fossem obrigatórias.

2. Escolha Eleitoral: Perguntava-se aos sujeitos em quem votariam.

b. Medidas Psicológicas:

1. Crenças na Eficácia Eleitoral: Perguntava-se aos sujeitos se o seu voto nas eleições seria útil, se sua participação ajudaria a mudar as coisas, se estariam dispostos a participar da campanha, se políticos e partidos eram úteis, etc. O conjunto de itens permitiu construir uma escala de crença na Eficácia Política.

2. Identificação Partidária: Perguntava-se aos sujeitos se tinham ou não simpatia por algum partido.

3. Visão da Estrutura Sócio-Política: Perguntava-se ao sujeitos pelos setores da sociedade que representariam tanto o seu partido de simpatia ou partido ideal, quanto os partidos considerados opostos. Cruzando ambas informações obtinha-se a visão que o eleitor possuía da estrutura sócio-política do país.

c. Medidas Psicossociológicas:

1. Participação nas Organizações da Sociedade Civil

Gouveia et al. (1997) pediram aos eleitores que indicassem, numa lista de 12 formas de associação ou organização da sociedade civil, o grau de participação em cada uma delas. Posteriormente realizaram uma análise fatorial que mostrou a existência de 03 tipos gerais de organização: sócio-política, trabalhista, e comunitária.

\section{Resultados}


A fim de verificar a viabilidade do Modelo Psicossociológico como método eficaz para o estudo do comportamento eleitoral, foi utilizada a Regressão Múltipla Gradual para analisar as diversas relações sugeridas pelo modelo. Analisando-se o modelo da esquerda à direita foi encontrado para cada variável o melhor conjunto de preditores entre as variáveis da coluna anterior. As variáveis nominais foram transformadas em dummy variables. A Tabela 1 mostra os resultados obtidos em forma de coeficientes de regressões parciais.

Pode-se observar, entre a primeira e a segunda coluna da Tabela 1, que os fatores sócio-demográficos mostram algumas relações significativas com as diversas formas de participação social. Primeiramente, constata-se que os eleitores que participam em uma ou várias das organizações sociais estudadas apresentam os mais altos graus de escolaridade $(\mathrm{rp}=.18)$ e pertencem às classes sociais mais favorecidas $(\mathrm{rp}=.10)$. Analisando-se por separado as diversas formas de participação social, observa-se, no que concerne às organizações sócio-políticas, que os eleitores com maior grau de instrução são os que possuem os índices de maior participação neste tipo de organização (rp = .10). Já a participação em organizações trabalhistas, relaciona-se positivamente com o grau de instrução $(r p=.36)$, a idade $(r p=.15)$ e o gênero ( $\mathrm{rp}=.13$ ). Isto significa que são os eleitores com maior grau de escolaridade, mais velhos e do sexo masculino que mais participam neste tipo de organização. Finalmente, observa-se que são os eleitores mais idosos que mais participam nas organizações comunitárias ( $\mathrm{rp}=$ .12).

As setas entre a segunda e a terceira coluna da Tabela 1 expressam as mediações existentes entre as diversas formas de participação social e as variáveis psicológicas. A participação em organizações sociais relaciona-se positivamente com a eficácia eleitoral $(\mathrm{rp}=.15)$. Isto indica que eleitores que freqüentam uma ou várias das organizações sociais estudadas são os que mais acreditam na eficácia da atividade eleitoral. As diversas formas de participação social apresentam relações significativas, na direção esperada, com o posicionamento dos eleitores na estrutura social (dado através do tipo de visão que o eleitor possui da representação social dos partidos). Os eleitores que desenvolveram 
Tabela 1. Coeficiente de regressão parcial, obtido através de análises de Regressão Múltipla Gradual nos dados da pesquisa realizada durante as Eleições Municipais de 1992

SÓCIO-DEMOGRÁFICAS


uma visão classista da estrutura social encontram-se engajados tanto em organizações sócio-políticas ( $\mathrm{rp}=.11$ ) quanto em organizações trabalhistas $(\mathrm{rp}=.23)$, enquanto que eleitores que possuem uma visão populista da estrutura social são os que mais participam de organizações comunitárias ( $\mathrm{rp}=.11$ ).

No mesmo nível de análise constata-se que a participação nas diversas formas de organização social pode ser considerada uma boa preditora do tipo de simpatia política dos eleitores. Os dados mostram que a participação trabalhista se relaciona positivamente com a simpatia por partidos de esquerda $(r p=.27)$ e negativamente com a simpatia por partidos de direita $(\mathrm{rp}=-.18)$. Por outro lado, os eleitores vinculados a organizações comunitárias $(\mathrm{rp}=.34)$ simpatizam com os partidos de direita.

Finalmente, entre a terceira e quarta coluna da Tabela 1 observamse as relações encontradas entre as variáveis psicológicas e aspectos do comportamento eleitoral. A eficácia eleitoral apresenta uma relação positiva com a disposição do eleitor a exercer o ato de votar $(\mathrm{rp}=.43)$. No que concerne ao posicionamento dos eleitores na estrutura social, observa-se que aqueles que adotam uma visão classista da estrutura social votam no candidato do partido de esquerda $(r p=.43)$. Já no que diz respeito à identificação partidária, a análise dos dados mostra que os eleitores identificados com os partidos de esquerda foram os que mais votaram nos candidatos de esquerda $(\mathrm{rp}=.57)$ e os que menos votaram no candidato populista $(\mathrm{rp}=-.52)$ e no de direita $(\mathrm{rp}=-.22)$.

\section{Conclusões}

No conjunto, os resultados confirmam as principais relações propostas no Modelo Psicossociológico da Figura 2. Assim, os fatores sócio-demográficos, mostram uma certa relação com as diversas formas de participação social. Cabe destacar, primeiramente, que os eleitores com maior grau de instrução são os que participam mais, tanto das organizações sócio-políticas como das trabalhistas. Estas últimas incluem os sindicatos urbanos e as associações de profissionais

liberais. Deve-se salientar, por um lado, que grande parte destas associações, em João Pessoa, é constituída por funcionários públicos 
26 L. Camino, E. A. da Silva e S. M. de Souza

que possuem um bom nível de escolaridade (Camino, 1993). Por outro lado, movimentos sócio-políticos como ecológicos, culturais, estudantis, pais e mestres e partidos, são formados, geralmente, por pessoas de nível educacional elevado.

A constatação de que os eleitores que possuem os mais baixos graus de escolaridade se encontram entre aqueles que não participam das organizações sociais estudadas, justifica-se pelo fato de que estes eleitores pertencem às classes sociais menos favorecidas, não tendo, condições de adquirir uma boa base educacional. Estes resultados confirmam diversas observações nas quais o grau de instrução mostra ser um fator importante na participação social dos cidadãos (Camino, 1993).

Qual é a influência da participação social na participação dos eleitores no processo eleitoral? Uma primeira constatação refere-se ao fato de que eleitores que participam das organizações sociais estudadas são os que mais acreditam na eficácia das atividades eleitorais. Poderse-ia pensar que a crença na eficácia eleitoral levaria a uma maior participação no processo eleitoral. Mas, de fato, Gouveia et al. (1997) constaram que só 30\% dos entrevistados estariam dispostos a participar na campanha eleitoral, embora metade da amostra admitisse a utilidade do ato de participar na campanha. Gouveia et al. (1997) explicam esta incongruência (uma relativa crença na utilidade da política e uma fraca participação efetiva do eleitor) na distinção que o eleitor faz entre sua participação concreta nesta campanha e a disposição a participar de campanhas futuras que possam vir a motivá-lo mais. Com este discurso os autores denunciam uma certa incapacidade dos partidos e candidatos em arregimentar uma maior mobilização política.

No que se refere a aspectos mais qualitativos da participação política, o Modelo Psicossociológico considera que a participação social é a base do desenvolvimento de matrizes ideológicas que, por sua vez, influenciam os eleitores a participar em atividades específicas do processo eleitoral.

Neste sentido, observa-se que as diversas formas de participação social modelam visões próprias no que se refere à estrutura social. Assim, a participação em organizações sócio-políticas e em organiza- 
ções profissionais, parece desenvolver uma visão da estrutura social que opõe de um lado os trabalhadores e do outro a classe dominante. Esta representação da realidade denomina-se de "visão classista" (Camino, 1993; Torres, 1992). Já a "visão populista", que indica o tipo de representação que opõe, de um lado, os mais necessitados, "o povão", e do outro, as elites política, intelectual e econômica, parece desenvolver-se na participação em organizações comunitárias, as quais tradicionalmente centram-se nas práticas assistencialistas de lideranças do tipo carismática ou religiosa.

A visão da estrutura social, enquanto matriz ideológica, influencia a escolha eleitoral. Nesta pesquisa observa-se que aqueles que possuem uma visão classista da estrutura social tendem a votar no candidato do partido de esquerda.

Estudos anteriores (Camino et al., 1995; Da Costa et al., 1994) mostraram que existe, entre estudantes universitários, uma relação estreita entre a ideologia do partido de simpatia e o tipo de representação da estrutura social. Portanto, não é de estranhar que o tipo de participação social esteja relacionada também à simpatia partidária.

A simpatia partidária é considerada por Lamounier (1978) o elemento-chave na compreensão das estruturas psicológicas subjacentes à participação eleitoral. Esta pesquisa mostra que as relações de simpatia ou de antagonismo com os partidos desenvolvemse na participação em organizações distintas. Constata-se que os eleitores participantes de organizações trabalhistas simpatizam mais com os partidos de esquerda e nutrem pouca simpatia por partidos de direita. Por outro lado, os eleitores que participam de organizações comunitárias, típicas das periferias de João Pessoa, tendem a se identificar mais com os partidos de direita.

Finalmente, observa-se que os simpatizantes de partidos de esquerda votam mais no candidato de esquerda e menos nos candidatos populistas e de direita.

Pode-se concluir, portanto, que o conjunto de Análise de Regressão Múltipla, efetuado nos dados da pesquisa desenvolvida durante as eleições de 1992 por Gouveia et al. (1997) parece confirmar 
28 L. Camino, E. A. da Silva e S. M. de Souza

a capacidade preditiva do Modelo Psicossociológico proposto neste trabalho na Figura 2. Mas deve-se considerar que as diversas seções do Modelo não têm o mesmo poder preditivo. Assim, as relações entre fatores sócio-demográficos e formas de participação social, embora significativas, explicam pouco da variabilidade dos dados. Já as relações entre as variáveis mediacionais e os diversos aspectos do voto mostram coeficientes elevados, significando que as variáveis antecedentes explicam expressiva porcentagem de variabilidade dos aspectos do voto.

De fato este modelo adequa-se perfeitamente à teoria mais ampla proposta por Camino (Camino, 1996c; Camino e Da Costa, 1994) sobre os processos de socialização política. Esta concepção de socialização se ajusta à necessidade de articular o psicológico no estudo da política (Doise, 1976). Nesta perspectiva, tanto a identidade social dos indivíduos, construída pelo sentimento de pertença a grupos sociais, quanto as alternativas políticas, formadas pelos interesses dos diversos grupos sociais, são consequiências das formas concretas que tomam as relações intergrupais no interior de uma determinada sociedade. Esta abordagem postula que a identidade dos indivíduos e a representação sócio-política dos partidos, como percebidas pelos indivíduos, estão intimamente relacionadas, e que esta relação é função da participação do sujeito nas organizações da sociedade civil (Camino 1996b).

A partir destes pressupostos, Camino (1996c) apresenta diversos estudos de socialização política (Ismael, Maciel, Brandão \& Camino, 1995; Lima \& Camino, 1995; Maciel, Brandão, Ismael \& Camino, 1996) que sugerem um modelo de socialização, o qual além de apontar a importância do desenvolvimento de certas estruturas cognitivas como condições prévias de aprendizagem e, também, a existência de mecanismos clássicos de aprendizagem, mostra a necessidade de se estudar a participação dos jovens nas diversas organizações da sociedade. É através desta participação ativa que um grupo constrói, conjuntamente com os sujeitos que a ele pertencem, os valores e normas que formam a identidade social desses sujeitos. 
Nesta perspectiva os jovens não só se adaptariam a grupos já existentes, mas participariam de grupos onde ativamente constróem suas normas e suas identidades sociais. Considera-se, portanto, que na dinâmica social não são os indivíduos que se socializam individualmente, mas são os grupos que se socializam na dinâmica das relações que mantêm com os outros grupos. Assim, os indivíduos se socializam na medida em que participam de grupos que estão ativamente construindo um determinado sistema político, nas relações entre eles e relações com o sistema como um todo. A socialização política, portanto, não se limita a um processo de aprendizado individual, mas constitui uma função essencial de sobrevivência, tanto para o sistema como um todo, como para os diversos setores sociais que o integram.

É neste sentido que o Modelo Psicossociológico propõe-se a estudar o voto, situando-o no processo político global. Aliás, não só os adolescentes, mas também os eleitores adultos vivem continuamente processos de socialização política, nos quais as diferentes formas de participação em organizações da sociedade desempenham um papel fundamental.

Por fim, há que se fazer uma ressalva sobre a aparente contradição entre a perspectiva (dialética) sobre a qual se assenta este estudo e o método utilizado no mesmo, que o faz configurar-se de um modo linear. Tal fato, no entanto, pode ser explicado pela atual ausência de um método através do qual se possa demonstrar, satisfatoriamente, a idéia do processo político-eleitoral como complexo, multideterminado e autoretroativo. Vale ressaltar que apesar das limitações impostas pelo método, teoricamente compreende-se o processo eleitoral como algo dinâmico que muda de acordo com a conjuntura e que, portanto, só pode ser analisado em função do contexto social.

\section{Referências}

Amado, V. A. (1988). O Engajamento nos Movimentos Sociais: origem do Zé Pião, movimento de oposição sindical da construção civil de João Pessoa. Dissertação de mestrado não-publicada, Universidade Federal da Paraíba, João Pessoa.

Balbachevsky, E. (1989). Stuart Mill: liberdade e representação. In F. Weffort (Org.), Os clássicos da política. São Paulo: Ática. 
30 L. Camino, E. A. da Silva e S. M. de Souza

Berelson, B. R., Lazarsfeld, P. F., \& McPhee, W. N. (1954). Voting: $a$ study of opinion formatiom in a Presidential campaing. Chicago: University of Chicago Press.

Berger, P. I. \& Luckmann, T. (1973). A construção social da realidade. Petrópolis: Vozes.

Bobbio, N. (1986). Representação política. In N. Bobbio., N. Matteucci, \& G. Pasquino (Orgs.). Dicionário de política, Brasília: Editora Universidade de Brasília.

Camino, L. (1992). Participation in civil society's organizations and electoral behavior. Caderno de Textos, 4, 1-27.

Camino, L. (1993, julho). Perfil psicossocial dos delegados ao IV $C E C U T / P B$. Comunicação apresentada na $45^{\text {a }}$ Renião Anual da SBPC, Recife, PE.

Camino, L. (1995). Da agressão individual às ações coletivas e políticas: reflexões sobre a construção do Núcleo de Estudos em Comportamento Político. Textos do Mestrado em Psicologia Social. João Pessoa: Editora Universitária da UFPb.

Camino, L. (1996a). Uma abordagem psicossociológica no estudo do comportamento político. Psicologia \& Sociedade. 1, 16-42.

Camino, L. (1996b). A sociedade na perspectiva da Psicologia: questões teóricas. In L. Camino, \& P. Menandro (Orgs.), A sociedade na perspectiva da psicologia: questões teóricas e metodológicas. Rio de Janeiro: ANPEPP.

Camino, L. (1996c). A socialização política: uma análise em termos de participação social. In L Camino, \& P. Menandro (Orgs.), A sociedade na perspectiva da Psicologia: questões teóricas e metodológicas. Rio de Janeiro: ANPEPP.

Camino, L., \& Da Costa, J. B. (1994). A participação política do adolescente: indicação de uma abordagem psicossocial a partir da noção de identidade. Temas de Psicologia, 1, 1-16.

Camino, L., Torres, A. R. \& Da Costa, J. B. (1995). Voto, identificación partidária, identidad social y construcción de la ciudadania. In O. D'adamo, V. G. Beaudoux, \& M. Monteiro (Orgs.), Psicologia de la acción política (pp.129-142). Buenos Aires: Paidós.

Campbell, A., Converse P. E., Miller. W. E., \& Stokes, D.E. (1960). The American voter. New York: Willey.

Campbell, A., Gurin, G., \& Miller. W. E. (1954). The voter decides. Evanston, Row, Peterson.

Cardoso, F. H. (1978). Partidos políticos. In P. Singer, \& V. C. Brant (Orgs.). São Paulo: o povo em movimento. Petrópolis: Vozes. 
Da Costa, J. B., Torres, A. R., Burity, M. H., \& Camino, L. (1994). Universidade: espaço institucional para o desenvolvimento político. Temas de Psicologia, 1, 17-36.

Doise, W. (1976). L'articulation psychossociologique et les relations entre groupes. Bruxelas: De Boeck.

Fisichiella, D. (1986). Comportamento eleitoral. In N. Bobbio, N. Matteucci, \& G. Pasquino (Orgs.), Dicionário de Política. Brasília: Editora Universidade de Brasília.

França, D. X. (1995). O comportamento político: uma análise psicossocial em termos de expectativas. Dissertação de mestrado não-publicada, Universidade Federal da Paraíba, João Pessoa.

Gouveia, R. (1995). O papel das crenças políticas no comportamento dos eleitores de João Pessoa em 1992 e 1994. Dissertação de mestrado não-publicada, Universidade Federal da Paraíba, João Pessoa.

Gouveia, R., França, D. X, Da Costa, J. B., \& Camino, L. (1997). O papel das crenças políticas no comportamento dos eleitores de João Pessoa em 1992 e 1994. In L. Lhullier, L. Camino, \& S. Salvador (Orgs.), Estudos do Comportamento Político: Abordagem Multidisciplinar. Florianópolis: Letras Contemporâneas.

Ismael, E., Maciel, C. M., Brandão, C. S., \& Camino, L. (1995). Categorização das diferenças sócio-econômicas em função do desenvolvimento cognitivo e do meio social. Psicologia: Reflexão e Crítica, 2, 249-272.

Lamounier, B. (1978). Presidente Prudente: o crescimento da oposição num reduto arenista. In F. W. Reis (Org.), Os partidos e o regime: a lógica do processo eleitoral brasileiro. São Paulo: Símbolo.

Lazarsfeld, P. F., Berelson, B., \& Gaudet, M. (1948). The people's choice. New York: Columbia University Press.

Le Bon, G. (1895). Psychologie des foules. Paris: Felix Alcan.

Lima, M. E., \& Camino, L. (1995). A política na vida de estudantes universitários: uma análise em termos de espaço político e de valores. In Lima Silva, M. J. (Org.), Iniciados (pp. 13-36). João Pessoa: Editora Universitária da UFPb.

Lima, M. L. (1993). Uma análise psicossociológica da ação coletiva de invadir terrenos urbanos: o caso da rua das Missões. Dissertação de mestrado não-publicada, Universidade Federal da Paraíba, João Pessoa.

Maciel, C. M., Brandão, C. S., Ismael, E. \& Camino, L. (1996). Desenvolvimento das explicações e expectativas de crianças e jovens no que concerne às desigualdades sócio-econômicas. Psicológica Reflexão e Crítica, 2, 383-401. 
32 L. Camino, E. A. da Silva e S. M. de Souza

Michels, R. (1982). Sociologia dos Partidos Políticos. (Tradução de Arthur Chaudon, 1982). Brasilía: Editora UnB (Texto original publicado em 1914).

Penna, M. (1989). Identidade e movimentos sociais: homogeneidade ou aliança política e trabalho. Revista Mestrado Ciências Sociais, 7, 71-77.

Reicher, S. D. (1984). The St. Pauls' riot: an explanation of the limits of crowd action in terms of a social identity model. European Journal of Social Psychology, 14, 1-21.

Sighele, S. (1954). La foule criminelle (2a. ed.). Paris: Alcan. (Texto original publicado em1898).

Stuart Mill, J. (1981). Considerações sobre o governo representativo. (M. I. de L. Santos Jr., Trad.). Brasília: Editora Universidade de Brasília (Texto original publicado em 1861).

Tajfel, H. (1981). Human groups and social categories: studies in social psychology. Cambridge: Cambridge University Press.

Tarde, G. (1898). Le public et la foule. Review de Paris.

Torres, A. R. (1992). Uma análise psicossocial da identificação partidária dos estudantes da UFPb nas eleições de 1988, 1989 e 1990. Dissertação de mestrado não-publicada, Universidade Federal da Paraíba, João Pessoa.

Turner, J. C. (1981). The experimental social psychology of intergroup behavior. Chicago: The University of Chicago Press.

Vala, J. (1996). As representações sociais no quadro dos paradigmas e metáforas da Psicologia Social, In L. Camino (Org.), Conhecimento do outro e a construção da realidade social: uma análise da percepção e da cognição social. João Pessoa: Editora Universitária $\mathrm{UFPb}$. 


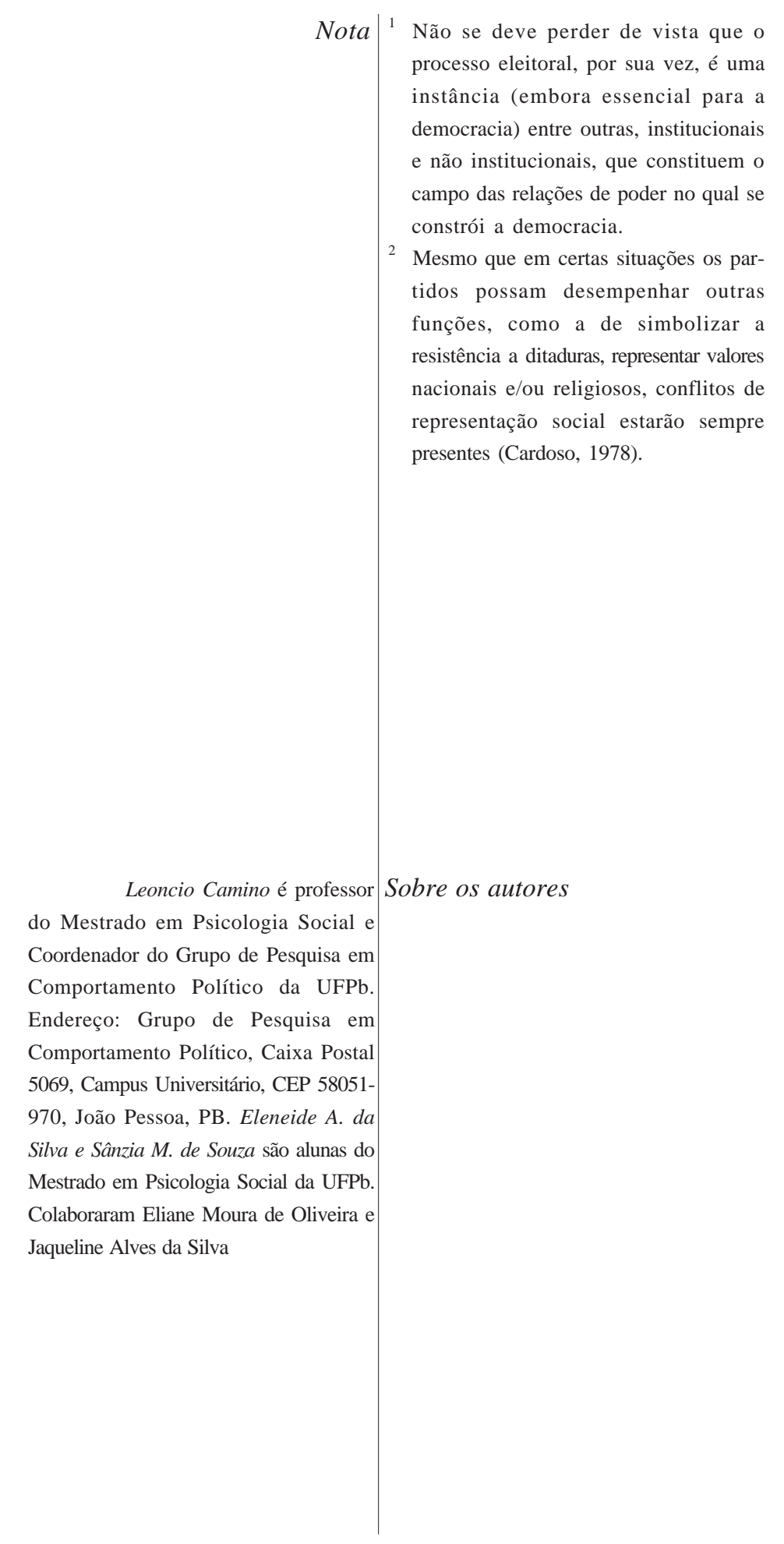

